\title{
Preparation and characterization of monosubstituted porphyrins immobilized on nanosilica
}

\author{
EBRAHIM AHMADI*, ALI RAMAZANI, ASEMEH MASHHADI-MALEKZADEH, \\ ZAHRA HAMDI and ZAHRA MOHAMADNIA ${ }^{\dagger}$ \\ Department of Chemistry, University of Zanjan, P.O. Box 45195-313, Zanjan, Iran \\ 'Department of Chemical Engineering, University of Zanjan, P.O. Box 45195-313, Zanjan, Iran
}

MS received 28 May 2013; revised 1 September 2013

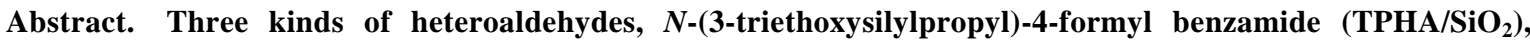
were prepared by the reaction of terephthalaldehydic acid with different silica supports such as hexagonal SBA-15, spherical SBA-15 and amorphous $\mathrm{SiO}_{2}$ for comparison purposes. Anchoring of this aldehyde to different supports allows the synthesis of mono-substituted porphyrins without the production of di-, tri- and tetra-substituted porphyrin side products. The exclusion of the aforementioned side products during the synthesis of monosubstituted porphyrins greatly reduced the complexity during purification of the product. Absorption spectrophotometry was performed on silica gel immobilizing porphyrin (CPTTP), free base tetraphenylporphyrin $\left(\mathrm{H}_{2} \mathrm{TPP}\right)$ and heteroaldehydes (TPHA/SiO $\left.{ }_{2}\right)$ using $\mathrm{UV}-\mathrm{Visible}$ instrument and confirmed the presence of porphyrin on the structure of CPTTP.
\end{abstract}

Keywords. Porphyrin; mesoporous silica; SBA-15; spherical; sensor; immobilization.

\section{Introduction}

Porphyrins are tetrapyrrole macrocycles and have a special structure with a big p-orbital on the carbonnitrogen framework. Because of the large conjugational effect of the tetrapyrrole macrocycle, porphyrins have special photophysical and chemical properties. Porphyrins and their metal complexes are found in many natural systems, where they play an essential role as photoactive, redox, guest-binding and catalytic entities. Because of their special properties, porphyrins have wide applications in many fields such as biomimetic catalysis, electrocatalysis, chemical and biological sensors, solar energy conversion and so on (Johanson et al 2005).

The synthesis of structurally complex porphyrins has seen tremendous progress in the past 30 years (Yang et al 2005) and is used as catalyst in the synthesis of many chemical compounds.

However, these porphyrins as homogeneous catalysts have some disadvantages: they may be easily destroyed and inactivated during the course of the reaction, and these expensive catalysts cannot be easily recovered after the reaction for reuse (Moghadam et al 2005; Naik et al 2005; Rahiman et al 2006).

These drawbacks limit the practical application of porphyrins in both synthetic chemistry and industrial process heavily. These shortcomings can be overcome by chemistry

*Author for correspondence (ahmadi@znu.ac.ir) anchoring porphyrins on suitable supports, such as silica (Ghiaci et al 2010), molecular sieves (Zhang et al 1999), polymer (Gao et al 2009), polystyrene (Anzenbacher et al 1997), counter-charged supports (Sacco et al 2001), xerogels (Sacco et al 2000) or zeolites, mesoporous SBA-15 (Fa et al 2006).

Many studies confirm that the anchoring of porphyrins on suitable support materials not only improves catalyst activity, stability and selectivity of the product because of the support environment, but also enables easy recovery and reuse of the catalyst through simple separation.

Among various solid support materials, SBA-15 was selected as a carrier because of its high transparency to visible light, wide surface area, and the ability to interact with different functional groups through covalent bonding (Latour et al 2005; Santos et al 2007; Zhang et al 2007).

The powerful explosivity and deleterious pollution of nitroaromatic compounds have concurrently raised worldwide concerns of public security and environmental problem, due to their wide production and use as explosives in military and engineering (Steinfeld and Wormhoudt 1998). So, the development of a new approach capable of rapid and cost-efficient detection of volatile chemical emission from explosives are highly desirable and necessary nowadays (Yinon 2003).

Interestingly, porphyrin-doped mesoporous silica showed a high fluorescence quenching sensitivity towards vapour of nitroaromatic compounds, comparable to the conjugated polymers. In comparison to conjugated polymer-based sensors, however, the fabrication of these porphyrin-doped 
mesoporous silica is very simple, the materials used are inexpensive, and the trapped organic sensing elements also become very stable in the inert silica matrix (GomezRomero and Sanchez 2004). Two key features of these mesostructured, viz. the porous structure and the large surface area (Fan et al 2000; Shea and Loy 2001; Pan and Lee 2005), are believed to be principally responsible for the remarkable sensing performance.

In the present work, to achieve a stable binding between porphyrin and support and increasing the porphyrin loading, we have developed a way to synthesis different heterogenized aldehyde and porphyrins. Free base tetraphenylporphyrin $\left(\mathrm{H}_{2} \mathrm{TPP}\right)$, heteroaldehyde (TPHA/ $\mathrm{SiO}_{2}$ ) and silica gel immobilizing porphyrin (CPTTP) were characterized using UV-Visible spectroscopy, FT-IR spectroscopy and CHN elemental analysis. The effect of different kinds of silica gel on porphyrin-loading efficiency are evaluated. Finally, the fluorescence response of the supported porphyrins to trace vapours of nitro-containing aromatics was investigated.

\section{Experimental}

\subsection{Materials}

Terephthalaldehydic acid (TPHA), benzaldehyde, 3-aminopropyltriethoxysilane (APTES), pyrrole, $N$-hydroxysuccinimide (NHS), $N, N^{\prime}$-dicyclohexylcarbodiimide (DCC), triethylamine $\left(\mathrm{Et}_{3} \mathrm{~N}\right)$ and $p$-chloranil were purchased from Merck company and used without further purification. Pyrrole was freshly distilled under vacuum and over potassium hydroxide. Tetrahydrofuran (THF) was refluxed over sodium with benzophenone as an indicator and distilled under nitrogen atmosphere before use. Hexane was distilled over $\mathrm{CaCl}_{2}$ prior to use. The spherical SBA-15 and hexagonal SBA-15 were synthesized according to our previous work (Ahmadi et al 2010; Mohamadnia et al 2010).

\subsection{Physicochemical characterizations of synthesized materials}

Preparative thin-layer chromatography (PTLC) was carried out on $20 \times 20 \mathrm{~cm}$ glass plates coated with silica gel ( $1 \mathrm{~mm}$ thick, Merck- $\mathrm{F}_{254}$ ). Melting points were measured on an Electrothermal 9100 apparatus fitted with a microscope. Fourier transform infrared (FT-IR) spectroscopy (Jasco $6300 \mathrm{FT}-\mathrm{IR}$ ) was taken in $\mathrm{KBr}$ pellets to confirm the structure of synthesized materials. ${ }^{1} \mathrm{H}-\mathrm{NMR}$ and ${ }^{13} \mathrm{C}-\mathrm{NMR}$ spectra were recorded using a Bruker ARX 300 multinuclear spectrometer at $250 \mathrm{MHz}$ instrument at room temperature using $\mathrm{CDCl}_{3}$ and DMSO- $d_{6}$ as solvent. Tetramethylsilane $\left(\mathrm{SiMe}_{4}\right)$ was used as an internal reference. UV-Vis spectra were recorded on a Shimadzu UV-160 spectrophotometer using acetone as solvent. UV-Vis spectra of both porphyrins and their supported types were recorded in a $10-\mathrm{mm}$ path length quartz cell, in a single-beam mode. The 'blank' was previously recorded and consisted of a support/acetone suspension. The porphyrin solutions were freshly prepared in the spectrally pure solvent at the concentration $2.5 \times 10^{-6} \mathrm{M}$. $\mathrm{X}$-ray powder diffraction data were obtained on a $\mathrm{D} / \mathrm{max}-$ $3 \mathrm{BX}$ diffractometer using $\mathrm{CuK} \alpha$ radiation of wavelength $0 \cdot 154 \mathrm{~nm}$. Nitrogen adsorption-desorption isotherms were obtained at $77 \mathrm{~K}$ using an OMNISORP (TM) 100CX VER $1 \mathrm{G}$ adsorption apparatus. Samples were outgassed at $473 \mathrm{~K}$ for at least $8 \mathrm{~h}$ in vacuum prior to measurements. The supports were deposited on a sample holder and sputtered with gold. The morphologies were observed on an SEM (SIRION, FEI, USA). Elemental analysis was performed by a CHN analyser system (Elementar, model Vario EL III).

\subsection{Synthesis of supports}

2.3a Synthesisof spherical SBA-15: Spherical SBA-15 (SBA-15(Sp)) was synthesized using tetraethylorthosilicate (TEOS) as the silica source, Pluronic $123\left(\mathrm{EO}_{20}-\right.$ $\mathrm{PO}_{70}-\mathrm{EO}_{20}$, poly(ethylene oxide)-block-poly(propylene oxide)-block-poly(ethylene oxide)-block) as template, cetyltrimethyl ammonium bromide (CTABr) as cosurfactant and ethanol as cosolvent (Ma et al 2003). Typically, $0.30 \mathrm{~g}$ of triblock copolymer P123 and $0.05 \mathrm{~g}$ of CTABr were dissolved in a solution formed by mixing $6 \mathrm{~mL}$ of $2 \mathrm{M} \mathrm{HCl}, 3 \mathrm{~mL} \mathrm{H}_{2} \mathrm{O}$ and $2.5 \mathrm{~mL}$ ethanol. Then $1 \mathrm{~mL}$ of TEOS was added into the aqueous solution at room temperature under magnetic stirring. The mixture was aged at $80^{\circ} \mathrm{C}$ for $5 \mathrm{~h}$ under static condition and then was allowed to age at $130{ }^{\circ} \mathrm{C}$ for $12 \mathrm{~h}$. The white precipitate was recovered by filtration, dried at $90{ }^{\circ} \mathrm{C}$ for $24 \mathrm{~h}$ and calcined in air at $550{ }^{\circ} \mathrm{C}$ for $6 \mathrm{~h}$ to remove the templates.

2.3b Synthesis of hexagonal SBA-15: Hexagonal SBA15(SBA-15(Hex)) material was synthesized according to the procedure described by Zhao et al (1998) using pluronic 123 as template. In a typical preparation, $4 \mathrm{~g}$ of pluronic was dissolved in $30 \mathrm{~g}$ of water and $120 \mathrm{~g}$ of $2 \mathrm{M}$ $\mathrm{HCl}$ solution with stirring at $35^{\circ} \mathrm{C}$. Then $8.50 \mathrm{~g}$ of TEOS was added to the solution with stirring at $35^{\circ} \mathrm{C}$ for $20 \mathrm{~h}$. The mixture was aged at $80^{\circ} \mathrm{C}$ overnight under static conditions. The solid product was filtered off, washed and air-dried at room temperature. The template was removed from the as-made mesoporous material by calcination in air at $550{ }^{\circ} \mathrm{C}$ for $6 \mathrm{~h}$ to remove the templates.

\subsection{Synthesis of $\mathrm{N}$-(3-triethoxysilylpropyl)-4-formyl benzamide (1)}

$N$-(3-triethoxysilylpropyl)-4-formyl benzamide (1) was prepared according to the literature method with a little change (Choithani et al 2006). In a round-bottom flask, 
TPHA $(3.2 \mathrm{mmol}, 0.53 \mathrm{~g})$ was dissolved in dry THF $(40 \mathrm{~mL})$. Then the solution was cooled to $0{ }^{\circ} \mathrm{C}$. NHS $(4.8 \mathrm{mmol}, 0.55 \mathrm{~g})$ and DCC $(3.84 \mathrm{mmol}, 0.79 \mathrm{~g})$ were added respectively. The reaction mixture was allowed to stir for $3 \mathrm{~h}$ at room temperature. Finally, the reaction mixture was filtered to remove the dicyclohexylurea formed during the reaction. Then 3-aminopropyltriethoxysilane (3-APS) $(3.84 \mathrm{mmol}, 0.89 \mathrm{~mL})$ and triethylamine $(3.84 \mathrm{mmol}, 0.53 \mathrm{~mL})$ was added to the filtrate under nitrogen atmosphere with stirring for $18 \mathrm{~h}$ at room temperature. Next, the solvent was evaporated under vacuum to $\sim 1 / 3$ of its initial volume and filtered to remove the 2,5-dioxo-pyrrolidin-1-olatetriethyl-ammonium. The residue was purified by chromatography on silica gel using ethyl acetate-hexane $(1: 3)$ as eluent to get $\mathrm{N}$-(3-triethoxysilylpropyl)-4-formyl benzamide (1).

Product (1) was purple crystals with $75 \%$ yield. $\mathrm{C}_{17} \mathrm{H}_{27} \mathrm{NO}_{5} \mathrm{Si}$, IR (KBr) $\left(v_{\max } \mathrm{cm}^{-1}\right): 3354(\mathrm{~N}-\mathrm{H}) ; 2944$ $\left(\mathrm{CH}_{3}\right) ; \quad 2866-2925 \quad(\mathrm{O}=\mathrm{C}-\mathrm{H}) ; 1712 \quad(\mathrm{CHO}) ; 1637$ $(\mathrm{NHC}=\mathrm{O}) ; 1697 \quad(\mathrm{C}=\mathrm{C}) ; 1542(\mathrm{~N}-\mathrm{CO}) ; 1201 \quad(\mathrm{C}-\mathrm{C})$; 1082, 767, $436(\mathrm{Si}-\mathrm{O}) ; 660(\mathrm{Si}-\mathrm{C})$.

${ }^{1} \mathrm{H}-\mathrm{NMR}\left(250 \mathrm{MHz}, \mathrm{CDCl}_{3}\right): \delta_{\mathrm{H}} 10 \cdot 03[1 \mathrm{H}, \mathrm{s}, \mathrm{CHO}]$, $7.9(4 \mathrm{H}, s, \mathrm{Ph}), 6.88(1 \mathrm{H}, s, \mathrm{NH}), 3.44\left(2 \mathrm{H}, m, \mathrm{CH}_{2} \mathrm{NH}\right)$, $1.74\left(2 \mathrm{H}, m, \mathrm{CH}_{2} \mathrm{CH}_{2} \mathrm{CH}_{2}\right), 0.68\left(2 \mathrm{H}, t, \mathrm{CH}_{2} \mathrm{Si}\right), 3.79(6 \mathrm{H}$, $\left.q, \mathrm{OCH}_{2}\right), 1 \cdot 18\left(9 \mathrm{H}, t, \mathrm{OCH}_{2} \mathrm{CH}_{3}\right) .{ }^{13} \mathrm{C}-\mathrm{NMR}\left(\delta\right.$ in $\left.\mathrm{CDCl}_{3}\right)$ : $7.85\left(\mathrm{CH}_{2} \mathrm{Si}\right), 18.23\left(\mathrm{OCH}_{2} \mathrm{CH}_{3}\right), 22.7\left(\mathrm{CH}_{2} \mathrm{CH}_{2} \mathrm{CH}_{2}\right)$, $42.34\left(\mathrm{CH}_{2} \mathrm{NH}\right), 58.5\left(\mathrm{OCH}_{2}\right), 129 \cdot 7,128.03(\mathrm{Ph}), 137.98$ $(\mathrm{C}-\mathrm{C}=\mathrm{O}), \quad 140 \cdot 15 \quad(\mathrm{C}-\mathrm{CHO}), \quad 166.36 \quad(\mathrm{C}=\mathrm{O}), \quad 191.59$ (CHO). Elemental analysis: calculated for $\mathrm{C}_{17} \mathrm{H}_{27} \mathrm{NO}_{5} \mathrm{Si}$ (found): C 57.76 (57.72), H 7.70 (7.60), N 3.96 (4.00), O $22.63(22.62)$ and Si $7.95(8.06)$.

\subsection{Synthesis of heterogenized aldehyde $\mathrm{SiO}_{2} / \mathrm{TPHA}$}

Compound (1) with $\mathrm{Si}(\mathrm{OEt})_{3}$ group was immobilized on synthesized SBA-15 (Hex), SBA-15 (Sp) and $\mathrm{SiO}_{2}$ (Amp) gel by the following procedure (Zheng et al 2000): $1 \mathrm{~g}$ of silica gel was first calcined in an electrical furnace at $150{ }^{\circ} \mathrm{C}$ for $3 \mathrm{~h}$ to remove physically absorbed water. Then the silica was added to the solution of aldehyde (1) $(2.4$ mmol, $0.847 \mathrm{~g})$ in dry hexane $(30 \mathrm{~mL})$. The mixture was stirred under reflux (about $73^{\circ} \mathrm{C}$ ) for $12 \mathrm{~h}$ under nitrogen atmosphere. Finally the activated light-yellow silica gel $\left(\mathrm{SiO}_{2} / \mathrm{TPHA}\right)$ was filtered, washed with ethanol and then dried at $80^{\circ} \mathrm{C}$ for more than $12 \mathrm{~h}$. The contents of aldehyde group were measured by way of elemental analysis.

\subsection{Preparation of heterogenized porphyrin $\mathrm{SiO}_{2} /$ CPTPP}

Preparation of heterogenized porphyrin was performed using the Alder-Longo procedure with some changes (Adler et al 1967). In a 250-mL round-bottom flask, equipped with a teflon-coated magnetic stirring bar, benzaldehyde $(1.2 \mathrm{~mL}, 12 \mathrm{mmol})$ was added to the suspension of $\mathrm{SiO}_{2} /$ TPHA $(1 \mathrm{~g})$ in propionic acid $(140 \mathrm{~mL})$. The solution was stirred at $140{ }^{\circ} \mathrm{C}$ for $1 \mathrm{~h}$. In a separate flask, a solution of $40 \mathrm{~mL}$ propionic acid in freshly distilled pyrrole ( $1 \mathrm{~mL}, 14.4 \mathrm{mmol})$ was added drop-wise to the previous solution at least $15 \mathrm{~min}$. Then the solution was refluxed for $1 \mathrm{~h}$ at $140{ }^{\circ} \mathrm{C}$.

The reaction mixture was cooled and allowed to stand overnight under air atmosphere. After filtering, the solid product was washed several times with hot water and methanol (1:9) solution and chloroform in order to remove unreacted reagents such as pyrrole, benzaldehyde, tetraphenylporphyrin and impurities. Then it was soxhlated with chloroform and methanol for $48 \mathrm{~h}$ to remove all organic material non-covalently bounded to the support. The final solid was dried to constant weight under vacuum, and they were namely the functional silica $\mathrm{SiO}_{2} / \mathrm{CPTPP}$ on which 5-(4-carboxyphenyl)-10,15,20-triphenylporphyrin (CPTPP) was immobilized.

\subsection{Determination of porphyrin immobilization yields}

One gram heterogenized porphyrin was added to $200 \mathrm{~mL}$ $0 \cdot 1 \mathrm{M} \mathrm{HCl}$. The mixture was refluxed at $90{ }^{\circ} \mathrm{C}$ for $48 \mathrm{~h}$. Then the porphyrin in the support released and extracted with chloroform. A solution of porphyrin $(0.5 \mathrm{mg})$ in chloroform $(100 \mathrm{~mL})$ was used as reference and its OD value at $410 \mathrm{~nm}$ was measured.

\section{Results and discussion}

The synthesis of monosubstituted porphyrins can be achieved by utilizing many methods that have been developed (Lindsay Smith et al 2000). However, the most common and direct methodology for synthesis of these monosubstituted porphyrins are to condense a mixture of pyrrole, benzaldehyde and the appropriately substituted benzaldehyde in $4: 3: 1$ ratio. This leads to the synthesis of the desired monosubstituted porphyrin along with a mixture of tetraphenylporphyrin, and di-, tri- and tetrasubstituted compounds. One strategy for preparation of these compounds has been explored, mainly based on heterogenization of an aromatic aldehyde and consecutive porphyrin formation.

\subsection{Characterization of supports}

X-ray pattern of as-synthesized SBA-15(Hex) prepared using $\mathrm{EO}_{20} \mathrm{PO}_{70} \mathrm{EO}_{20}$ (Pluronic P123) showed four wellresolved peaks that can be indexed as $\left(\begin{array}{lll}1 & 0 & 0\end{array}\right),\left(\begin{array}{lll}1 & 1 & 0\end{array}\right)$, $\left(\begin{array}{lll}2 & 0 & 0\end{array}\right)$ and $\left(\begin{array}{lll}2 & 1 & 0\end{array}\right)$ diffraction peaks associated with p6mm hexagonal symmetry (figure 1). The intense $\left(\begin{array}{lll}1 & 0 & 0\end{array}\right)$ peak reflected a $d$ spacing of $87 \AA$, corresponding to a large unit cell parameter ( $a=90 \AA$ ) (Zhao et al 1998). 
Table 1. Structural parameters of synthetic and commercial supports.

\begin{tabular}{llccccr}
\hline Sample & Support & $S_{\mathrm{BET}}\left(\mathrm{m}^{2} / \mathrm{g}\right)$ & $d_{\mathrm{p}}(\AA)$ & $V_{\mathrm{p}}(\mathrm{mL} / \mathrm{g})$ & $d_{100}(\AA)$ & $b_{\mathrm{p}}(\AA)$ \\
\hline 1 & $\mathrm{SiO}_{2}(\mathrm{Amp})$ & 500 & 60 & $0 \cdot 75$ & 74 & $12 \cdot 7$ \\
2 & $\mathrm{SBA}-15(\mathrm{Hex})$ & 479 & $35 \cdot 8$ & $0 \cdot 51$ & 87 & $32 \cdot 4$ \\
3 & $\mathrm{SBA}-15(\mathrm{Sp})$ & 894.5 & 106 & $3 \cdot 6$ & 103 & $6 \cdot 5$ \\
\hline
\end{tabular}

$S_{\mathrm{BET}}$, BET specific surface area; $V_{\mathrm{p}}$, specific pore volume; $d_{\mathrm{p}}$, average pore diameter, obtained from $\mathrm{BJH}$ adsorption data, $d_{\mathrm{p}}=4 V_{\mathrm{p}} / S_{\mathrm{BET}} ; d_{100}$, XRD interplanar spacing; $b_{\mathrm{p}}$, pore wall thickness, $b_{\mathrm{p}}=$ $\left(a_{0}-d_{\mathrm{p}}\right) / 2, a_{0}=(2 / \sqrt{ } 3) d_{100}$.

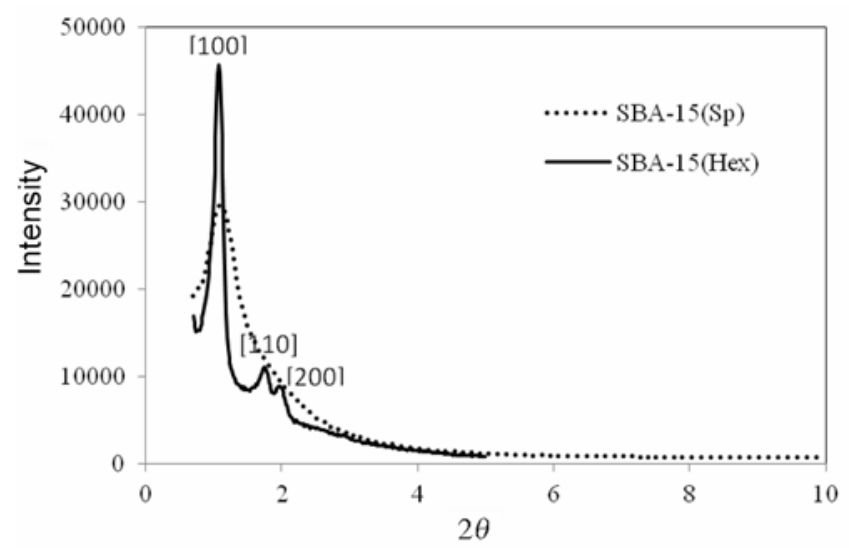

Figure 1. X-ray diffraction pattern of SBA-15(Hex) and SBA-15(Sp) supports.

Table 1 summarizes the textural properties of SBA-15 support derived from nitrogen adsorption-desorption isotherm plot and pore size distribution curve. Table 1 also displays the textural properties of commercial amorphous silica used as a reference support for comparison purposes.

Scanning electron microscopy was used to determine the size and morphology of the supports. Figure 2(a) shows SBA-15(Hex) particles have a tubular structure with length of $0.9-1.5 \mu \mathrm{m}$ and diameter of $0.2-0.3 \mu \mathrm{m}$, and each particle consists of many hexagonal nanochannels.

As shown in figure 2(b), SBA-15(Sp) obtained at $80{ }^{\circ} \mathrm{C}$ for $5 \mathrm{~h}$ exhibited a perfectly spherical morphology with diameters ranging from 3 to $6 \mu \mathrm{m}$ (table 1 ). The addition of co-solvent in the starting solution causes the decrease of the polarity of the solvent and thus decreases the rate of nucleation and growth of the meso-structured products because of the slower TEOS hydrolysis and mesostructure assembly, which could contribute to the formation of silica spheres with smooth surfaces (Zhao et al 2000; Kosuge et al 2001; Zhao et al 2002). Small-angle X-ray diffraction (SAXD) pattern from SBA-15(Sp) clearly shows Bragg peaks with $d$ spacing of $10.3 \mathrm{~nm}$ that is attributed to ordered mesoporous materials with spherical structure as shown in figure 1.

$\mathrm{N}_{2}$ adsorption-desorption isotherms and the corresponding BJH pore size distribution curves of SBA$15(\mathrm{Sp})$ are shown in figure 3. Sample exhibited type IV isotherms with well-defined steps associated with the filling of the mesopores due to capillary condensation (figure 3a). The physicochemical properties of the obtained SBA-15(Sp) were summarized in table 1 .

As shown in figure 3(b), the calculated average pore sizes for SBA-15(Sp) is $10 \cdot 6 \mathrm{~nm}$, which is consistent with the XRD result. It is noted that the pore volumes for SBA-15(Sp) was $3.6 \mathrm{~cm}^{3} \mathrm{~g}^{-1}$ much higher than those for the reported SBA-15(Hex) particles $\left(0.51 \mathrm{~cm}^{3} \mathrm{~g}^{-1}\right)$ (see table 1).

\subsection{Synthesis of $\mathrm{N}$-(3-triethoxysilylpropyl)-4-formyl benzamide (1)}

$N$-(3-triethoxysilylpropyl)-4-formyl benzamide (1) was synthesized from a binary mixture of TPHA and 3aminopropyltriethoxysilane (3-APS) using a modification of literature method (Choithani et al 2006) as showed in scheme 1.

FT-IR spectra (figure 4) of aldehyde (1) showed broadbond at 3354 and $2944 \mathrm{~cm}^{-1}$ related to $\mathrm{N}-\mathrm{H}$ and $\mathrm{C}-\mathrm{H}$ stretching vibrations. Weak peaks at 2925 and $2866 \mathrm{~cm}^{-1}$ assigned to $\mathrm{C}-\mathrm{H}$ stretching of aldehyde. Characteristic peaks at 1542, 1634, 1697 and $1712 \mathrm{~cm}^{-1}$ attributed to $\mathrm{C}-\mathrm{N}, \mathrm{C}=\mathrm{C}, \mathrm{C}=\mathrm{O}(\mathrm{CHO})$ and amide $(\mathrm{NHC}=\mathrm{O})$, respectively. In the case of compound (1), peaks at 1201, 1067 and $660 \mathrm{~cm}^{-1}$ related to stretching $\mathrm{C}-\mathrm{C}, \mathrm{Si}-\mathrm{O}$ and $\mathrm{Si}-\mathrm{C}$, respectively. Bending vibration of $\mathrm{Si}-\mathrm{O}$ group was appeared at 754 and $436 \mathrm{~cm}^{-1}$.

\subsection{Characterization of heterogenized aldehyde $\left(\mathrm{SiO}_{2} / \mathrm{TPHA}\right)$}

As shown in scheme 2, aldehyde (1), that bears a $\mathrm{Si}(\mathrm{OEt})_{3}$ group, was anchored to different inorganic supports $\left(\mathrm{SiO}_{2}\right.$ (Amp), SBA-15(Hex), SBA-15(Sp)) by controlled hydrolysis of $\mathrm{Si}-\mathrm{OEt}$ bond and reaction with the free silanols on the surface of the supports.

The incorporation of the organic parts into the silica structure can be monitored by analysing FT-IR spectra of the different compounds. Figure 5 compares FT-IR spectra of heterogenized aldehyde (1), SBA-15(Hex) and aldehyde (1). The infrared spectrum of the silica gel shows the typical $\mathrm{Si}-\mathrm{O}$ lattice vibrations: a strong and broad band at $1064 \mathrm{~cm}^{-1}$ with a shoulder at $1200 \mathrm{~cm}^{-1}$; a 

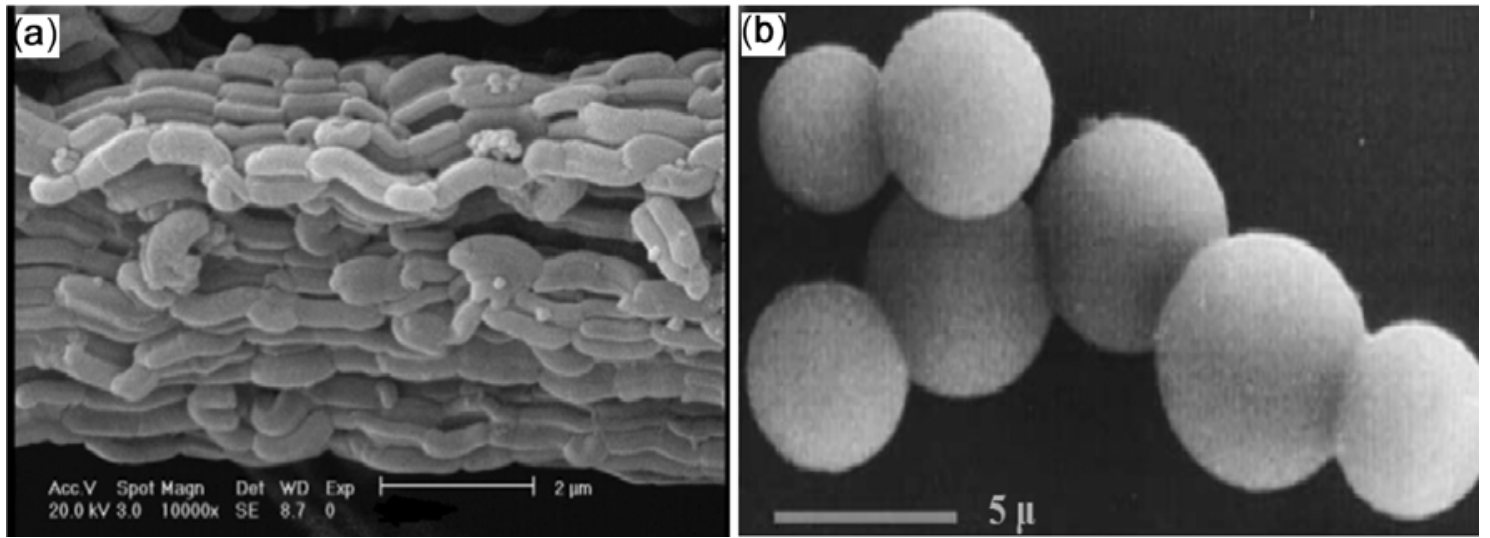

Figure 2. SEM micrographs of (a) tubular structure of SBA-15(Hex) and (b) SBA-15(Sp) prepared at $80{ }^{\circ} \mathrm{C}$ for $5 \mathrm{~h}$ with ethanol co-solvent.
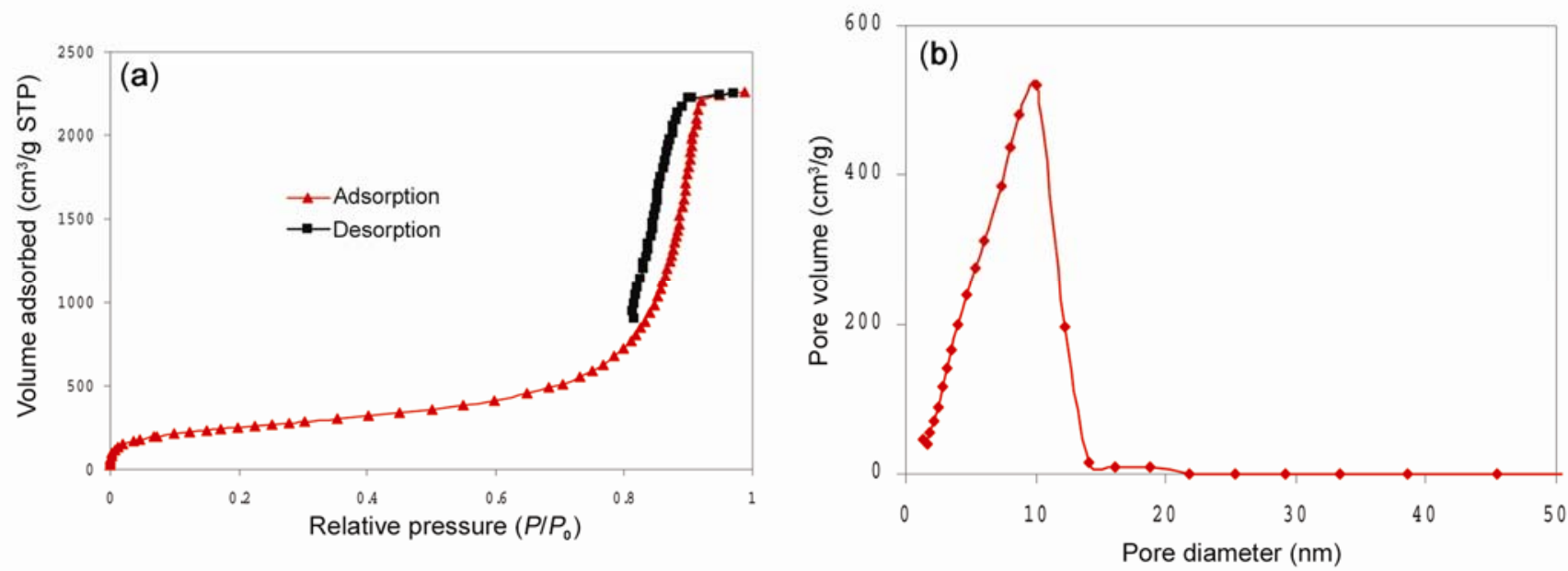

Figure 3. $\mathrm{N}_{2}$ adsorption-desorption isotherms (a) and pore size distribution curves from the adsorption branch (b) of SBA$15(\mathrm{Sp})$.

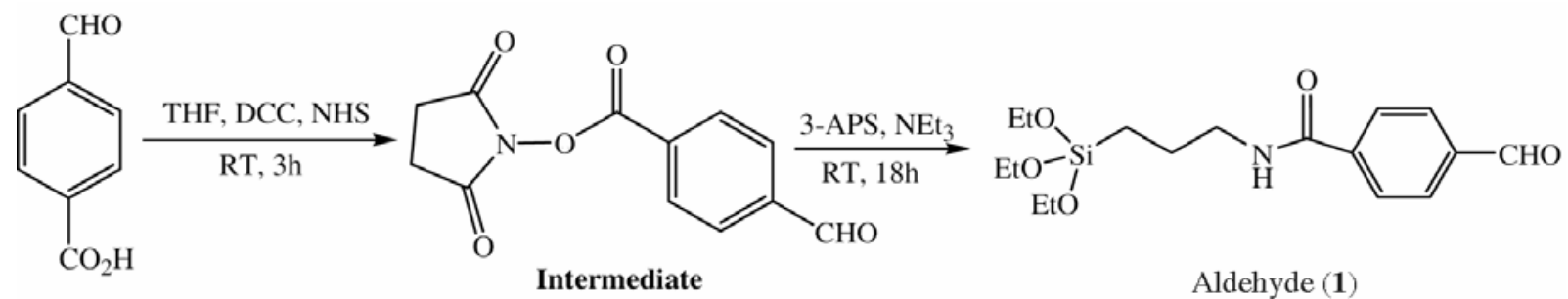

Scheme 1. Preparation of aldehyde (1).

strong band at $445 \mathrm{~cm}^{-1}$ and a medium intensity band at $790 \mathrm{~cm}^{-1}$. Furthermore, a very broad band centred at $3380 \mathrm{~cm}^{-1}$ with medium intensity due to $\mathrm{O}-\mathrm{H}$ stretching vibrations assigned to isolated surface $\mathrm{Si}-\mathrm{O}-\mathrm{H}$ groups are observed (Luts et al 2007; Qu et al 2008). In the spectrum of SBA-15(Hex)/TPHA, bands at 1712, 1697 and $1637 \mathrm{~cm}^{-1}$ that are attributed to stretching vibration absorption of $\mathrm{C}=\mathrm{O}$ bond of amides, $\mathrm{C}=\mathrm{C}$ (phenyl) and amide $\mathrm{N}-\mathrm{C}$ bond, respectively. The weak bands in the region $2866-2925 \mathrm{~cm}^{-1}$ are assigned to $\mathrm{C}-\mathrm{H}$ of aldehyde groups. All of the peaks confirm the reaction between ethoxysilane groups of compound (1) and the free silanols on the surface of the supports. Similar trends are observed in the case of the other silica derivatives $\mathrm{SiO}_{2}(\mathrm{Amp})$ and $\mathrm{SBA}-15(\mathrm{Sp})$. 


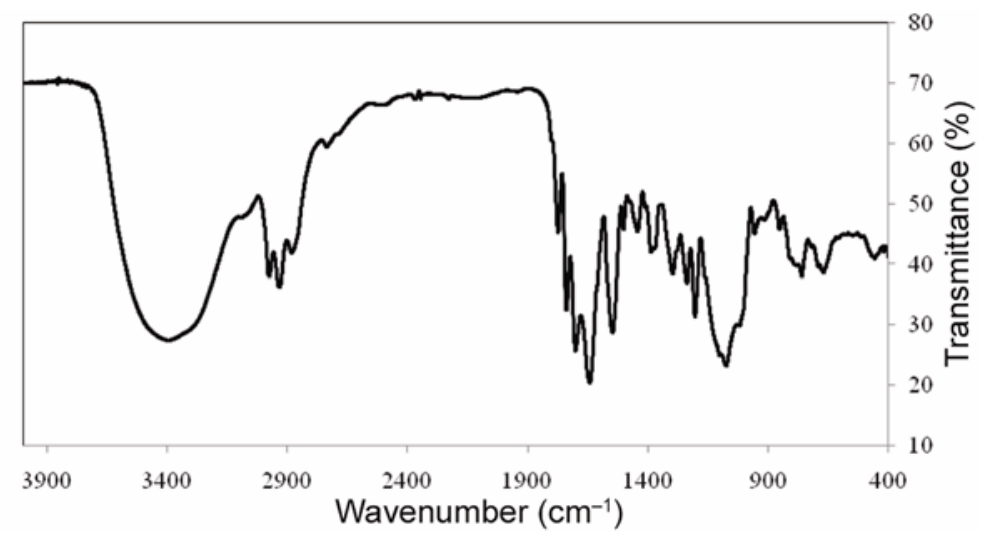

Figure 4. FT-IR spectra of $N$-(3-triethoxysilylpropyl)-4-formyl benzamide (1).

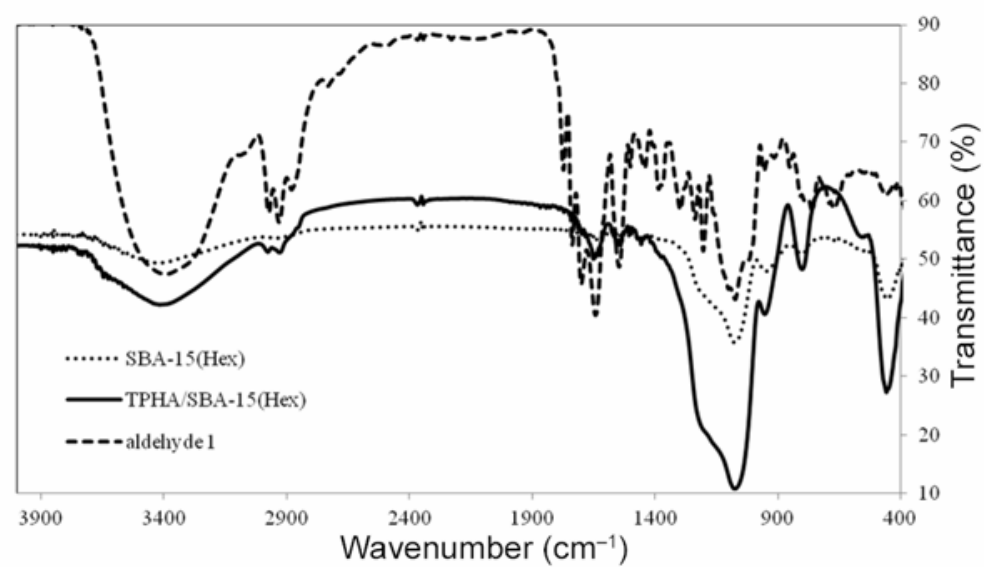

Figure 5. FT-IR spectra of SBA-15(Hex), SBA-15(Hex)/TPHA and aldehyde (1).

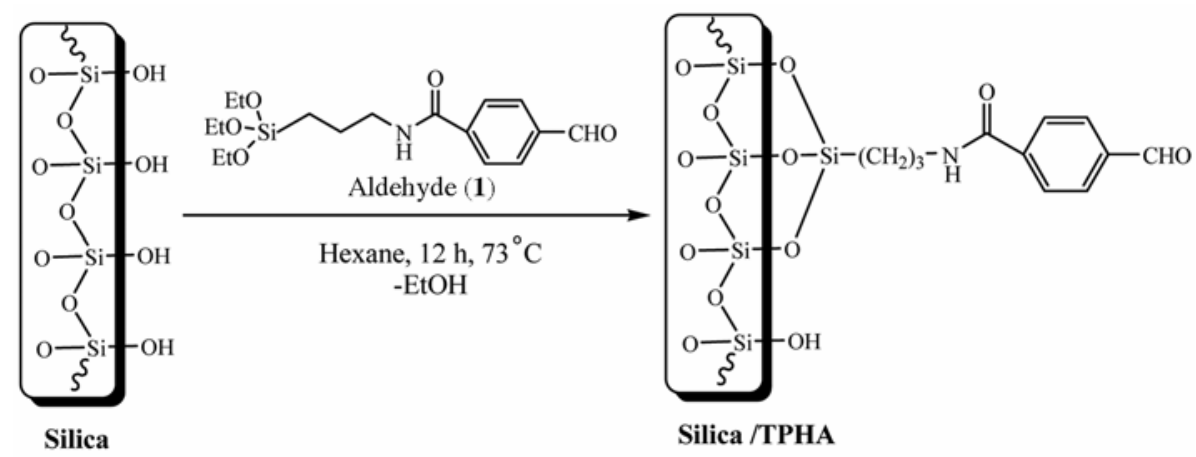

Scheme 2. Formation of heterogenized aldehyde.

Table 2 gives the immobilization results of different samples measured by elemental analysis. The content of aldehyde or porphyrin incorporated to the support is related to different factors: surface area, structural characteristics of supports and number of silanol groups that are accessible for grafting. The immobilization yield of aldehyde on SBA-15(Sp)is $0.79 \mathrm{mmol} \mathrm{g}^{-1}$ silica that is higher than SBA-15(Hex). This result is related to the higher specific surface area $\left(894.5 \mathrm{~m}^{2} \mathrm{~g}^{-1}\right)$ of SBA-15(Sp) compared with SBA-15(Hex) $\left(479 \mathrm{~m}^{2} \mathrm{~g}^{-1}\right)$ (table 1). As shown in scheme 3, amount of accessible hydroxyl groups for grafting at the surface of SBA-15(Sp) $>$ SBA-15(Hex) 
Table 2. Content of aldehyde or porphyrin anchored to the support $\left(\mathrm{mmol} \mathrm{g}^{-1}\right)$.

\begin{tabular}{lcccc}
\hline Sample & C content (\%) & H content (\%) & N content (\%) & $\begin{array}{c}\text { Immobilization yield } \\
(\mathrm{mmol} / \mathrm{g} \text { silica) }\end{array}$ \\
\hline SBA-15(Hex)/TPHA & $11 \cdot 2$ & $2 \cdot 2$ & $0 \cdot 9$ & $0 \cdot 65$ \\
SBA-15(Sp)/TPHA & $10 \cdot 3$ & $2 \cdot 1$ & $1 \cdot 1$ & $0 \cdot 79$ \\
SBA-15(Hex)/CPTPP & 18 & $2 \cdot 4$ & 2 & $0 \cdot 19$ \\
SBA-15(Sp)/CPTPP & $15 \cdot 7$ & $1 \cdot 8$ & $2 \cdot 3$ & $0 \cdot 2$ \\
\hline
\end{tabular}

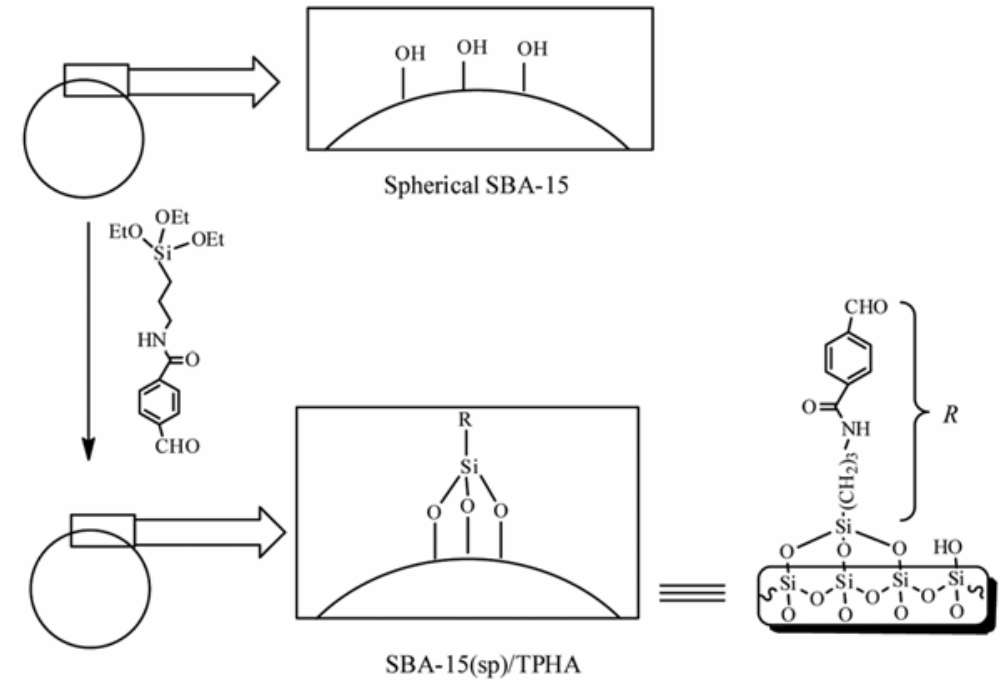

Scheme 3. Preparation of heterogenized aldehyde SBA-15(Sp)/TPHA.

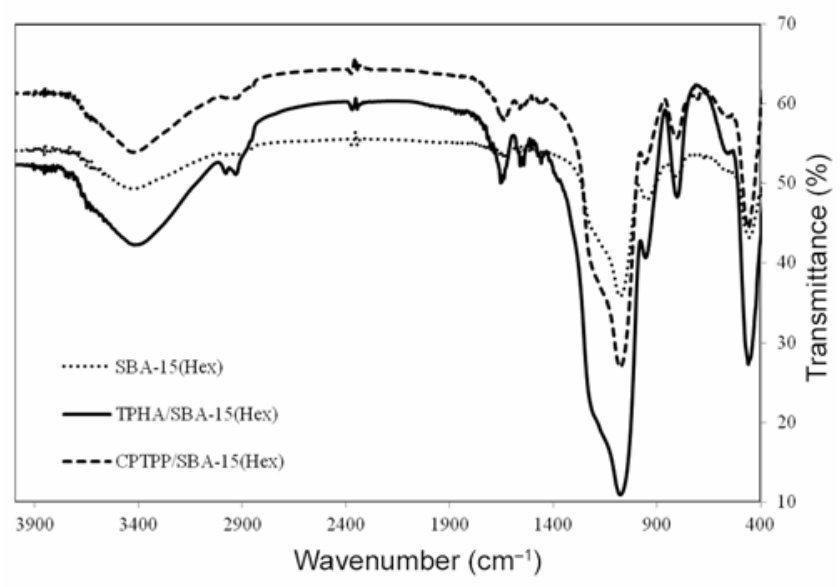

Figure 6. FT-IR spectra of SBA-15(Hex), SBA-15(Hex)/ TPHA and SBA-15(Hex)/CPTPP.

due to higher specific surface area. But in hexagonal SBA-15, low value of specific surface area and internal hydroxyl groups decrease the reaction probability and lead to lower aldehyde immobilization (scheme 4).

\subsection{Synthesis and characterization of heterogenized porphrin $\left(\mathrm{SiO}_{2} / \mathrm{CPTPP}\right)$}

In the next step, heterogenized aldehyde ( $\left.\mathrm{SiO}_{2} / \mathrm{TPHA}\right)$ was used for porphyrin synthesis using propionic acid as catalyst, as shown in scheme 5. Solids were soxhletextracted to remove all organic material non-covalently bounded to the support. We used different techniques for characterizing the structure of final immobilized material $\left(\mathrm{CPTPP} / \mathrm{SiO}_{2}\right)$ as described subsequently.

3.4a FT-IR technique: The weak bands in the region $2866-2925 \mathrm{~cm}^{-1}$ are assigned to $\mathrm{C}-\mathrm{H}$ of aldehyde groups. In FT-IR spectra of heterogenized porphyrin $\left(\mathrm{CPTPP} / \mathrm{SiO}_{2}\right)$ (figure 6), the characteristic absorption bands of $\mathrm{C}-\mathrm{H}$ aldehyde groups as described earlier disappeared completely, and intensity of absorption bands attributed to aldehyde groups in $1600-1720 \mathrm{~cm}^{-1}$ range, decreased (Zhou et al 2004). The aforementioned changes of absorption bands reveal that the Alder's reaction between TPHA/ $\mathrm{SiO}_{2}$ and pyrrole as well as benzaldehyde or substituted benzaldehyde in the reaction has occurred, and synchronous synthesis and immobilization of porphyrins on silica were achieved. In the case of the other supports such as $\mathrm{SBA}-15(\mathrm{Sp})$ and $\mathrm{SiO}_{2}(\mathrm{Amp})$, similar peaks were observed that confirm the preparation of porphyrin on the silica surface.

3.4b CHN elemental analysis: The loading of porphyrin in heterogenized aldehyde (1), based on $N$-contents from elemental analysis data is reported in table 2 and it ranges from 0.19 to $0.2 \mathrm{mmol} \mathrm{g}^{-1}$ depending on the support. As shown in scheme 5, nanochannels in SBA-15(Hex) act as 


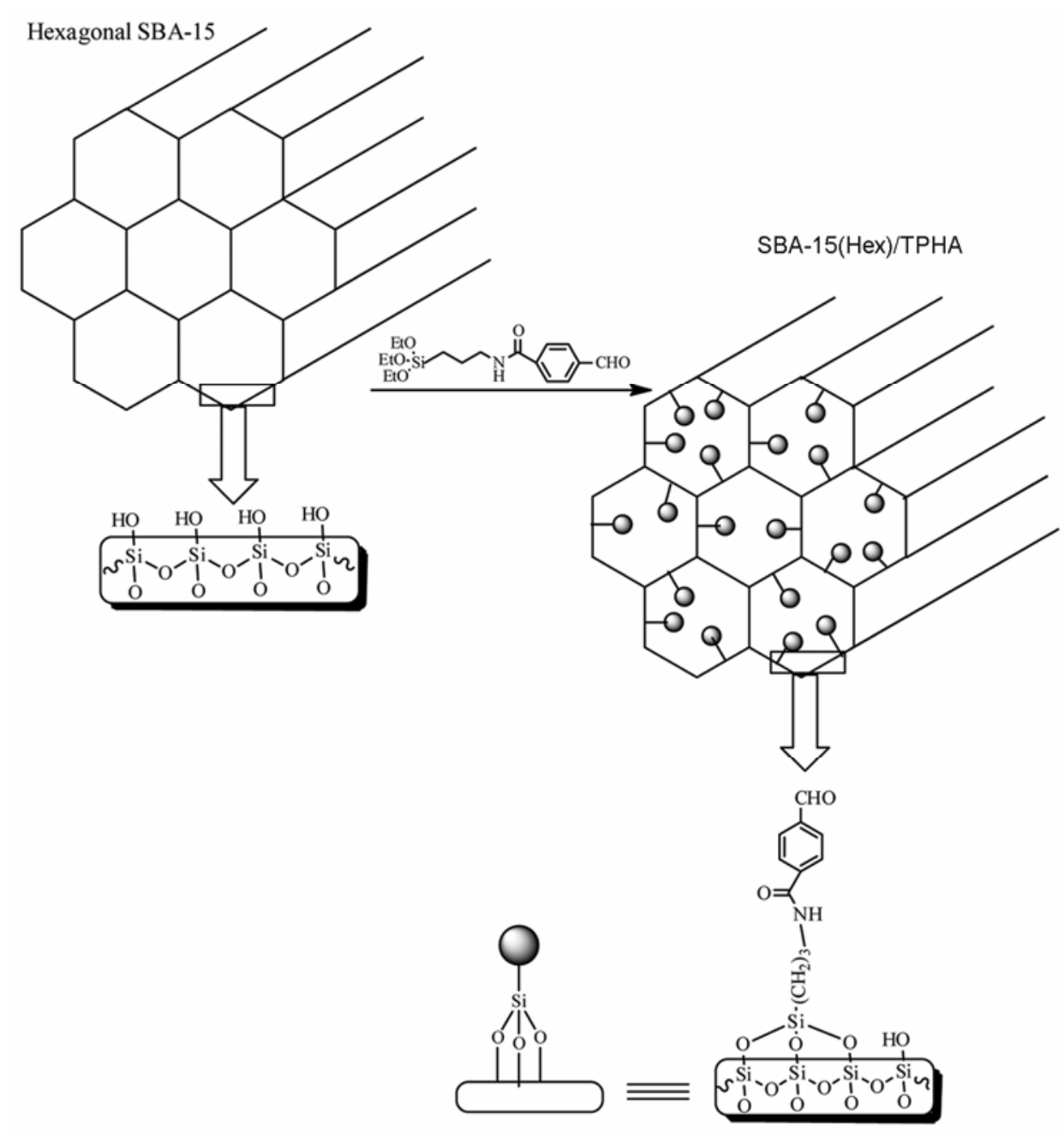

Scheme 4. Preparation of heterogenized aldehyde SBA-15(Hex)/TPHA.

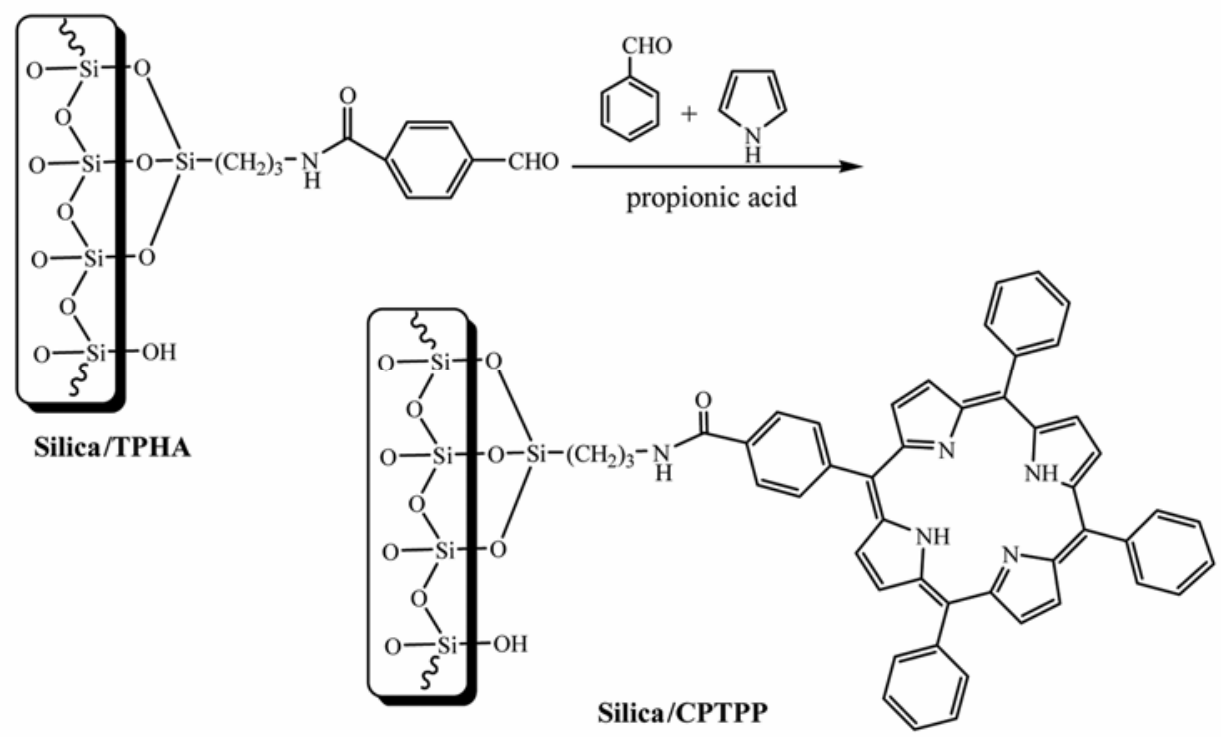

Scheme 5. Preparation of porphyrin-doped silica/TPHA. 


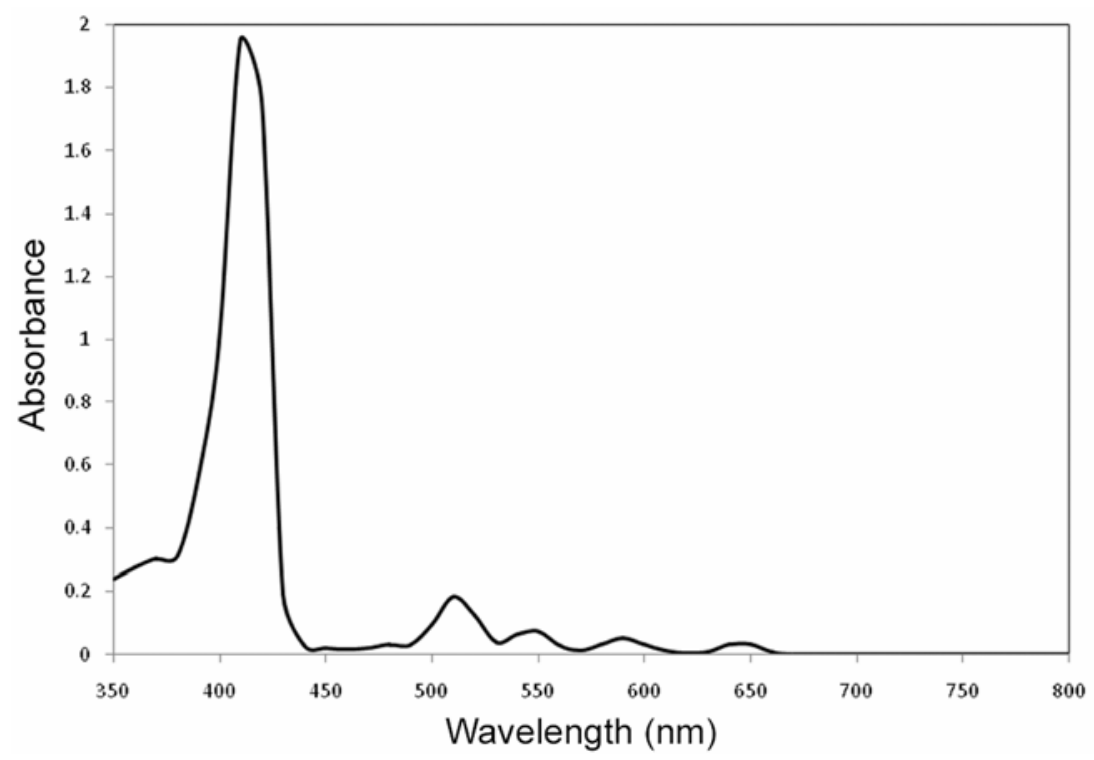

Figure 7. UV-Vis spectrum of free base 5-(4-carboxyphenyl)-10,15,20-triphenylporphyrin (CPTPP) in acetone.

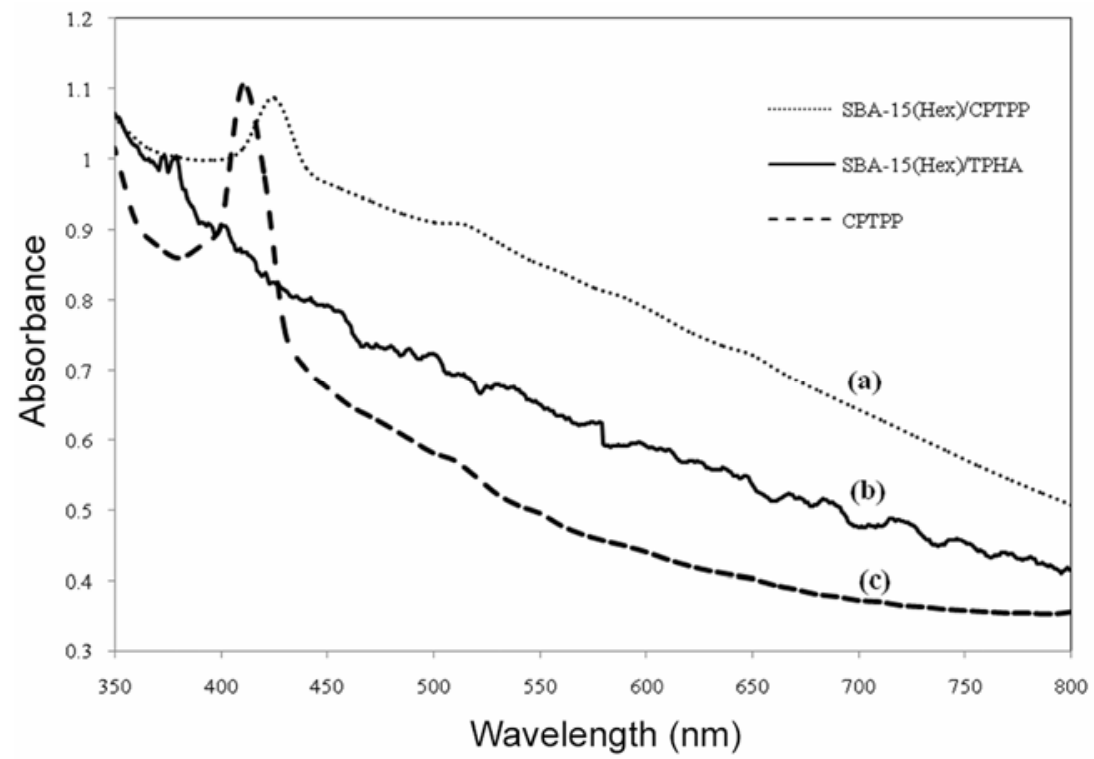

Figure 8. Comparative UV-Vis spectra of (a) SBA-15(Hex)/CPTPPin acetone, (b) SBA-15(Hex)/TPHA in acetone, (c) released porphyrin (CPTPP) from CPTPP/ SBA-15(Hex) after acidic hydrolysis.

nanoreactors, increase the probability of effective contacts between heterogenized aldehyde, benzaldehyde and pyrrole and increase the loading efficiency of porphyrin. But in the structure of SBA-15(Sp), lack of channel leads to the reaction at the surface of support. So in spite of the higher surface area of SBA-15(Sp), the loading of porphyrin on both supports are equal.

3.4c Characterization of supported porphyrins by UVVis spectroscopy: (A) Direct method - UV-Vis spectra of 5-(4-carboxyphenyl)-10,15,20-triphenylporphyrin (CPTPP) display etio type shape with the typical Soret band and the four $Q$ bands in the visible region, as presented in figure 7. The band around $410 \mathrm{~nm}$ is generated by the transition from $a_{1 \mathrm{u}}(\pi)-e_{\mathrm{g}}^{*}(\pi)$ and corresponds to the Soret band, and the other four absorption maxima around 510, 550,590 and $650 \mathrm{~nm}$ might be attributed to $Q$ bands corresponding to $a_{2 \mathrm{u}}(\pi)-e_{\mathrm{g}}^{*}(\pi)$ transitions.

$\mathrm{UV}-\mathrm{Vis}$ spectra of final immobilized material $\left(\mathrm{CPTPP} / \mathrm{SiO}_{2}\right)$ were obtained by immersing the solids in 


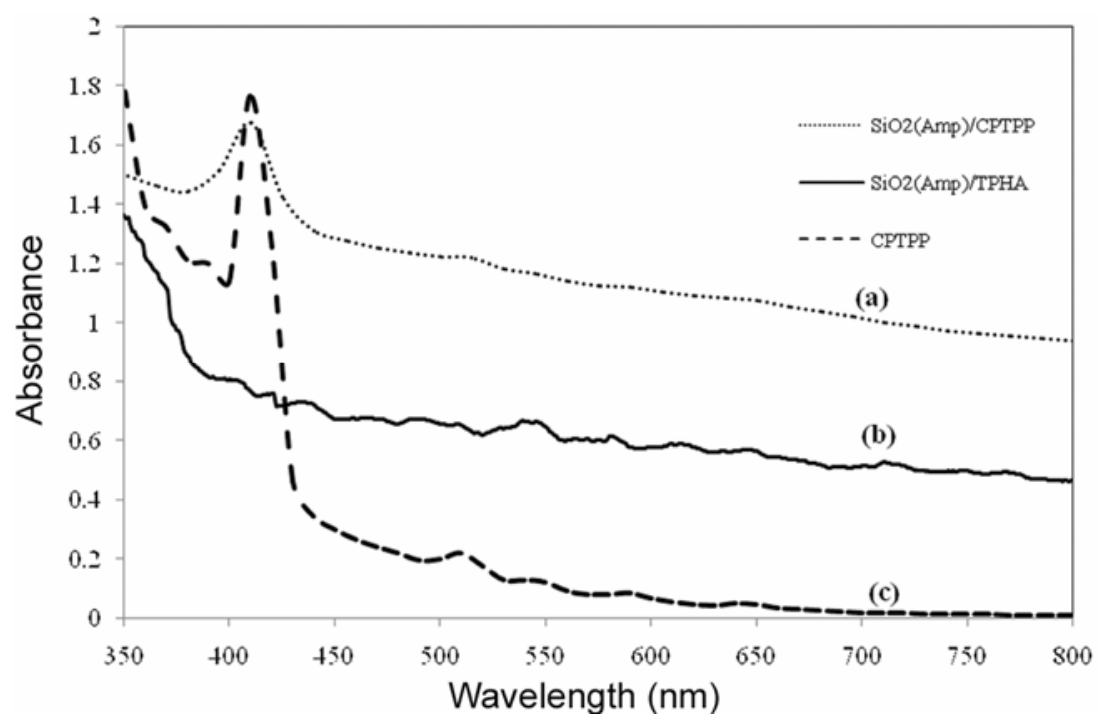

Figure 9. Comparative UV-Vis spectra of (a) $\mathrm{SiO}_{2}$ (amorphous)/CPTPP in acetone, (b) $\mathrm{SiO}_{2}$ (amorphous)/TPHA/in acetone, (c) released porphyrin (CPTPP) from $\mathrm{CPTPP} / \mathrm{SiO}_{2}$ (amorphous) after acidic hydrolysis.

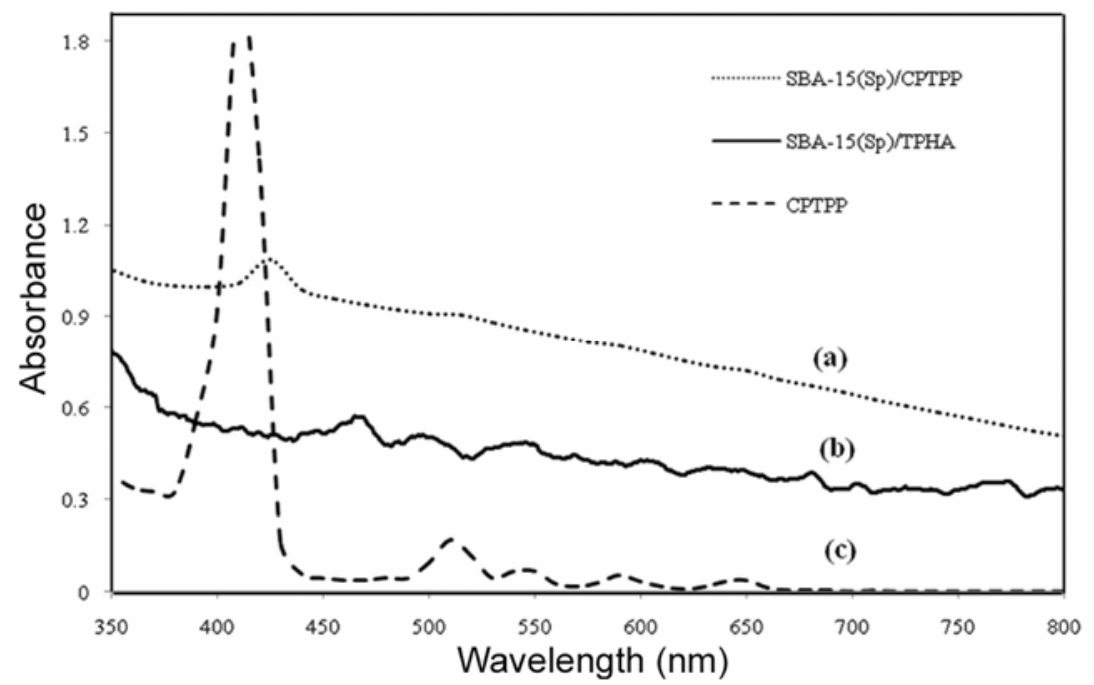

Figure 10. Comparative UV-Vis spectra of (a) SBA-15(Sp)/CPTPP in acetone, (b) SBA-15(Sp)/TPHA, (c) released porphyrin (CPTPP) from CPTPP/SBA$15(\mathrm{Sp})$ after acidic hydrolysis.

acetone that is shown in the figures 8(a), 9(a) and 10(a), respectively. UV-Vis characteristics peaks (Soret band and $Q$ bands absorption around 410, 510, 550, 590 and $650 \mathrm{~nm}$ ) of $\quad \mathrm{CPTPP} / \mathrm{SiO}_{2}(\mathrm{Amp}), \quad \mathrm{CPTPP} / \mathrm{SBA}-15(\mathrm{Hex})$ and CPTPP/SBA-15(Sp) (figures 8(a), 9(a) and 10(a)) were similar with free porphyrin (CPTPP) (figure 7), showing that the molecules of porphyrin are grafted onto $\mathrm{SiO}_{2}$.

$\mathrm{UV}-\mathrm{V}$ is spectra of TPHA/ $\mathrm{SiO}_{2}$ (figures $8(\mathrm{~b}), 9(\mathrm{~b})$ and 10(b)) have no characteristic peaks but the spectra of supported porphyrins show the Soret band at $410 \mathrm{~nm}$ almost at the same position as the free porphyrin but have much broader bands with lower relative intensity.

(B) Indirect method - Anther method was used to confirm the immobilization of porphyrin on supports. In this method, the final immobilized material $\left(\mathrm{CPTPP} / \mathrm{SiO}_{2}\right)$ hydrolysed under acidic condition that was explained in experimental section. Under acidic condition, the porphyrin in the support was released and measured by UV-Vis spectroscopy. The Soret band and $Q$ bands absorption around 410, 510, 550, 590 and $650 \mathrm{~nm}$ of released porphyrin (figures 8(c), 9(c) and 10(c)) qualitatively confirm that the porphyrin was supported on the silica surface.

\subsection{Application of supported-porphyrins as a TNT sensor}

Fluorescence response of supported porphyrins to trace vapours of nitro-containing aromatics was investigated by 

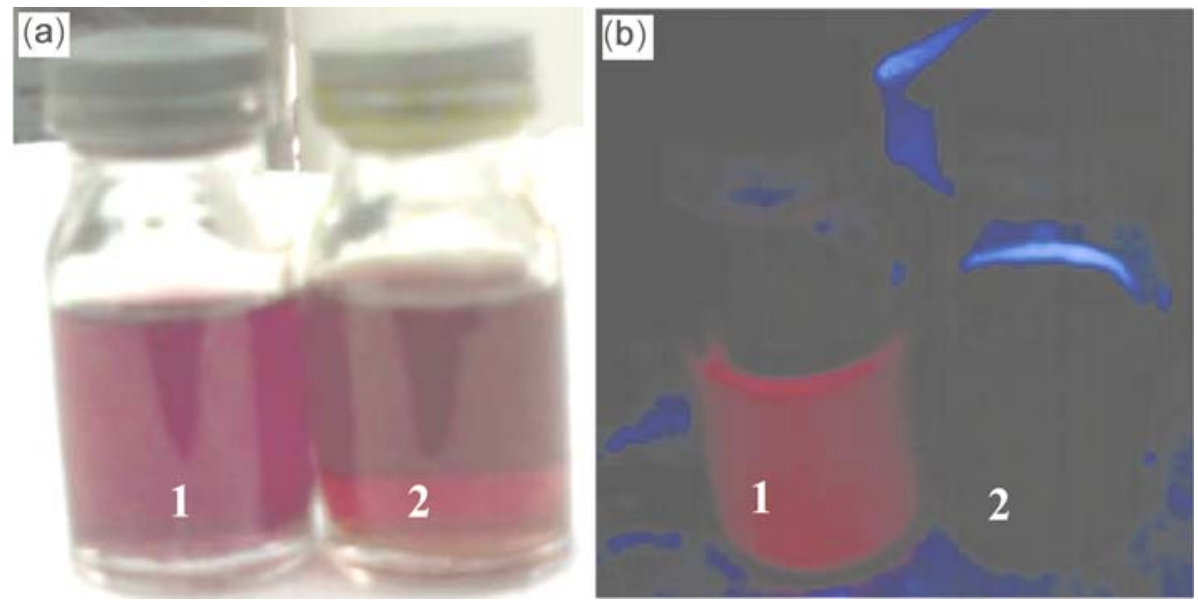

Figure 11. Images of (1) porphyrin suspension in dichloromethane and (2) porphyrin suspension in dichloromethane in the presence of 2-nitrotoluene under (a) visible light and (b) ultraviolet light.

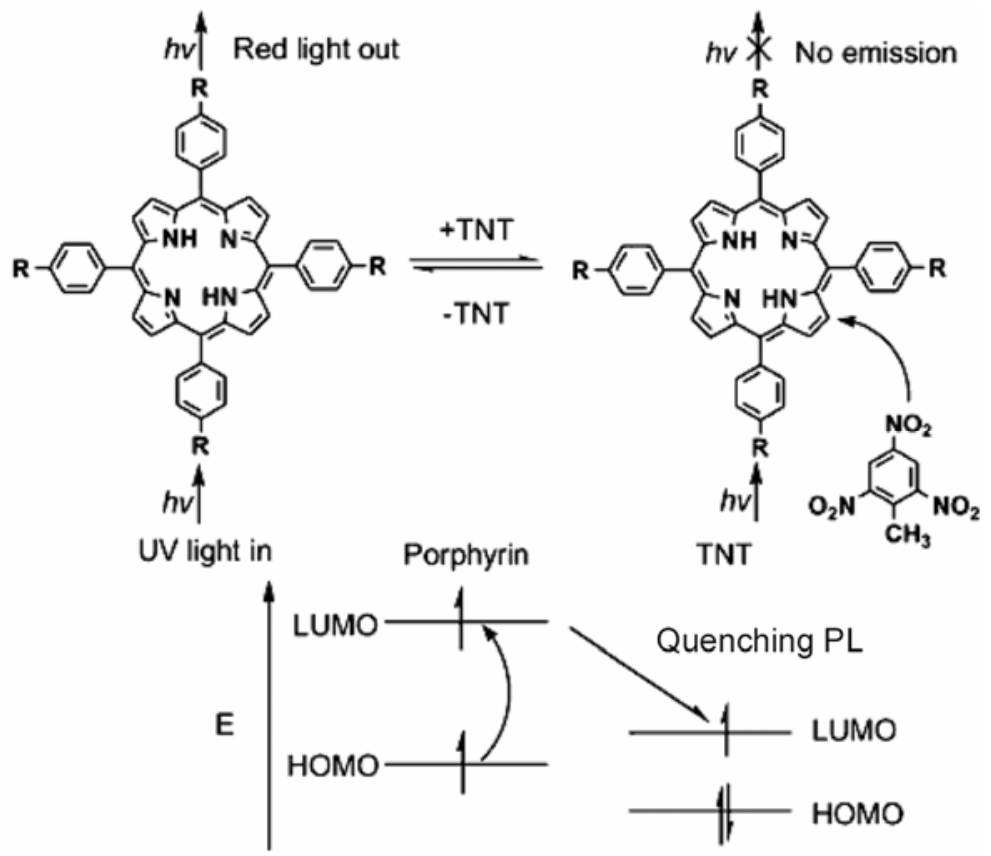

Scheme 6. Schematic diagram of electron-transfer mechanism for quenching the fluorescence of porphyrin by TNT molecule.

inserting the suspension of prepared supported porphyrins in dichloromethane into glass vial $(10 \mathrm{~mL})$ at room temperature. As shown in figure 11, vapour of nitroaromatic compound (2-nitrotoluene) was added to one suspension. Under visible light, both suspensions showed red colour. Under ultraviolet light, the sample in the presence of 2-nitrotoluene showed purple colour, but the suspension without nitroaromatic compound showed no change. The unique mesoporous structure provides a necessary condition for the facile diffusion of analytes to sensing elements while the large surface area considerably enhances the interaction sites between analyte molecules and sensing elements and thereby further improves the detection sensitivity. Final results including the influence of mesoporous size and structure of the formed supported porphyrinson sensing performance will be published shortly.

Scheme 6 shows a schematic diagram of the electrontransfer mechanism for the quenching of photoluminescence of the porphyrin dye with analyte.

\section{Conclusions}

The comparison of characterization results suggests that new heterogenized porphyrins can be easily synthesized by a widely applicable methodology, bearing a stable 
covalent bond with support. Synthetic method enables appropriate content of porphyrin to be added to the support. Mesostructured solids and well-structured all-accessible delaminated zeolites seem to be suitable supporters to immobilizing homogeneous porphyrins, both with very high surface areas and accessibility to reactants. The percentage of porphyrin incorporated to the support is higher in the case of SBA-15(Sp) with higher surface area. A higher surface area might be expected to yield higher immobilization, which is observed. On the other hand, independent nature of support, the heterogenized porphyrins are very stable materials having an extended catalytic life.

\section{Electronic Supplementary Material}

Supplementary material pertaining to this article is available on the Bulletin of Materials Science website (www.ias.ac.in/matersci).

\section{References}

Anzenbacher P, Kral V, Jursíkova K, Gunterova J and Kasal A 1997 J. Mol. Catal. A118 63

Adler A D, Longo F R, Finarelli J D, Goldmacher J, Assour J and Korsakoff L 1967 J. Org. Chem. 32476

Ahmadi E, Nekomanesh Haghighi M, Mohamadnia Z and Ramazani A 2010 J. Appl. Polym. Sci. 1183658

Choithani J, Kumar P and Gupta K C 2006 Anal. Biochem. 357 240

Fa H B, Zhao L, Wang X Q, Yu J H, Huang Y B, Yang M and Wang D J 2006 Eur. J. Inorg. Chem. 214355

Fan H et al 2000 Nature 40556

Gao B, Wang R and Zhang Y 2009 J. Appl. Polym. Sci. 112 2764

Ghiaci M, Molaie F, Sedaghat M E and Dorostkar N 2010 Catal. Commun. 11694

Gomez-Romero P and Sanchez C 2004 Functional hybrid materials (Weinheim: Wiley-VCH)

Johanson U, Marandi M, Sammelselg V and Tamm J 2005 J. Electroanal. Chem. 575267
Kosuge K and Singh P S 2001 Chem. Mater 132476

Lindsay Smith J R 2000 The porphyrin handbook (eds) K M Kadish, K M Smith and R Guilard (San Diego: Academic Press) p. 45

Luts T, Suprum W, Hofmann D, Klepel O and Papp H 2007 J. Mol. Catal. A: Chem. 26116

Latour V, Pigot T, Mocho P, Blanc S and Lacombe S 2005 Catal. Today 101359

Ma Y, Qi L, Ma J, Wu Y, Liu O and Cheng H 2003 Colloid. Surf. A: Physicochem. Eng. Aspects 2291

Moghadam M, Tangestaninejad S, Mirkhani V, Mohammadpoorbaltorkb I and Kargar H 2005 Bioorg. Med. Chem. 13 2901

Mohamadnia Z, Ahmadi E, Nekoomanesh M, Ramazani A and Salehi Mobarakeh H 2010 Polym. Int. 59945

Naik R, Joshi P, Umbarak S and Deshpande R K 2005 Catal. Commun. 6125

Pan J H and Lee W I 2005 New J. Chem. 29841

Qu R, Wang M, Sun C, Zhang Y, Ji C and Chen H 2008 Appl. Surf. Sci. 2553361

Rahiman A K, Rajesh K, Bharathi K S, Sreedaran S and Narayanan V 2006 Appl. Catal. A: Gen. 314216

Sacco H C, Ciuffi K J, Biazzotto J C, Zuccki M R, Leite C A P, Nascimento O R and Serra Iamamoto O A 2000 J. Non-Cryst. Solids 273150

Sacco H C, Iamamoto Y and Lindsay Smith J R 2001 J. Chem. Soc. Perkin Trans. 2181

Shea K J and Loy D A 2001 Chem. Mater. 133306

Steinfeld J I and Wormhoudt J 1998 Annu. Rev. Phys. Chem. 49 203

Santos S F et al 2007 J Colloid Interf. Sci. 305264

Yang Q, Streb K K and Borhan B 2005 Tetrahedron Lett. 46 6737

Yinon J 2003 Anal. Chem. 7599

Zheng S, Gao L and Guo J 2000 J. Solid-State Chem. 152447

Zhang X, Jin Z, Li Y, Li S and Lu G 2007 J. Power Sources 16674

Zhou Y, Schattka J H and Atonietti M 2004 Nano Lett. 4477

Zhang L, Sun T and Ying J Y 1999 Chem. Commun. 1103

Zhao D, Sun Q and Stucky G D 2000 Chem. Mater. 12275

Zhao J W, Gao F, Fu Y L, Jin W, Yang P D and Zhao D Y 2002 Chem. Commun. 752

Zhao D, Huo Q, Feng J, Chmelka B F and Stucky G D 1998 J. Am. Chem. Soc. 1206024 